\title{
Managing inflammatory bowel disease in adolescent patients
}

This article was published in the following Dove Press journal:

Adolescent Health, Medicine and Therapeutics

6 January 2014

Number of times this article has been viewed

\section{J Bishop' \\ DA Lemberg² \\ AS Day ${ }^{3}$}

'Paediatric Gastroenterology, Starship Children's Hospital,

Auckland, New Zealand; ${ }^{2}$ Department of Gastroenterology, Sydney

Children's Hospital, Sydney, Australia; ${ }^{3}$ Department of Paediatrics, University of Otago (Christchurch), Christchurch, New Zealand
Correspondence: Andrew Day Department of Paediatrics, University of Otago (Christchurch), Riccarton Avenue, Christchurch 8140, New Zealand

Phone +6433640747

Fax+6433640919

Email andrew.day@otago.ac.nz
Abstract: Increasing numbers of adolescents are being diagnosed with Crohn's disease or ulcerative colitis, the two main subtypes of inflammatory bowel disease. These young people face many short- and long-term challenges; one or more medical therapies may be required indefinitely; their disease may have great impact, in terms of their schooling and social activities. However, the management of adolescents with one of these incurable conditions needs to encompass more than just medical therapies. Growth, pubertal development, schooling, transition, adherence, and psychological well-being are all important aspects. A multidisciplinary team setting, catering to these components of care, is required to ensure optimal outcomes in adolescents with inflammatory bowel disease.

Keywords: adolescents, Crohn's disease, ulcerative colitis, therapy, multidisciplinary care

\section{Introduction}

The inflammatory bowel diseases (IBD) comprise two main subtypes: Crohn's disease (CD) and ulcerative colitis (UC). ${ }^{1,2}$ These incurable conditions lead to chronic inflammatory changes in the gastrointestinal tract that may manifest as pain, diarrhea, weight loss, and impaired linear growth. Although the exact pathogenesis of IBD is not yet elucidated, a number of recent advances have illustrated the importance of genetic elements, the intestinal microflora, and innate responses of the host. ${ }^{2}$ While both CD and UC may present at any age, the peak age of onset is between 15-35 years of age; consequently, many individuals are diagnosed while adolescents. ${ }^{3}$

The effects of IBD in adolescence extend far beyond the physical manifestations of the disease. Effective management of IBD in the adolescent demands an holistic model of care, with recognition of the many wider effects on the individual and their family.

Adolescence is a period of major physical, emotional, and psychological challenges. These include the establishment of identity, honing of cognitive abilities and social skills, shaping of belief systems, establishment of independence from parents, and development of adult relationships, including those of a romantic nature. ${ }^{4}$ Along with these key challenges, adolescents with IBD are also faced with the challenge of navigating the transition from family-centered pediatric care to an adult-oriented model of health care. This review will summarize some key aspects of IBD in adolescents, and present key principles for management of IBD in this age group.

\section{The inflammatory bowel diseases}

Although CD and UC share common elements, they also have specific differentiating features. CD encompasses inflammatory changes in any section of the gut, 
from the mouth to the anus. ${ }^{2}$ Perioral (eg, lip swelling) and perianal (eg, perianal fistula) manifestations may also occur. Endoscopically and histologically, the typical features of CD are aphthoid ulcers, deeper serpiginous ulceration, transmural inflammation, and patchy changes (skip lesions). The presence of non-caseating granulomata in the lamina propria is characteristic of $\mathrm{CD}$, but these are not universally present. Although most adolescents with CD have purely inflammatory changes at diagnosis, many will subsequently progress to develop structuring or fistulizing disease over time. ${ }^{5}$

On the other hand, UC is characterized by colonic inflammation, extending proximally from the rectum for a variable distance. ${ }^{2}$ Endoscopic features include granularity, ulceration, and increased friability. Histologically, the inflammatory changes are superficial and continuous. A small number of individuals diagnosed with IBD, including adolescents, will have endoscopic and histologic findings at the time of diagnosis that do not differentiate between UC and CD: the term IBD-unclassified (IBDU) should be used for this situation. ${ }^{6,7}$ Generally, with the passage of time and the evolution of the pattern and features of inflammation, IBDU is able to be reclassified as CD or UC. ${ }^{6,7}$ One report indicated that IBDU is reclassified as UC more commonly. ${ }^{8}$ Some adolescents may be classified as having indeterminate colitis. This term should be used when the distinction between UC and CD remains unclear, even after colectomy and histopathological examination of the resected colon. ${ }^{6,7}$

A number of large cohort studies illustrate that children and adolescents with CD and UC have more extensive disease at diagnosis (ie, involve more bowel length) and follow a more severe disease course over time, compared to adult cohorts. ${ }^{9,10}$ For instance, CD involves the upper gut (proximal to the terminal ileum) in more than $50 \%$ of children and adolescents, but is not noted commonly in adults. ${ }^{9,11}$ Furthermore, $\mathrm{CD}$ is more frequently panenteric in pediatric case series $(43 \%)$ than in adults $(3 \%) .{ }^{9}$ Overall, more extensive disease is also seen in adolescent UC. Up to three-quarters of children and adolescents with UC have pancolitis, while few have isolated proctitis. ${ }^{9}$ Furthermore, those who have proctitis or limited left-sided disease at diagnosis often have extension of disease in the subsequent 2 years. These features contrast greatly with the patterns seen in adults who are diagnosed with UC: many have left-sided disease or proctitis; early extension is less commonly seen. ${ }^{9}$

\section{The pathogenesis of IBD}

Although our current understanding of the pathogenesis of $\mathrm{CD}$ and UC is incomplete, it is clear that genetics, the gut flora, and host responses are three key elements. ${ }^{2}$ A large number of susceptibility genes are now recognized; many of these have important roles in elements of host defense, and some have a bias towards earlier onset of disease (including in adolescence). ${ }^{12-14}$ Although a number of microorganisms have been considered as putative causative agents for IBD, there are not yet data to implicate one individual organism, or group of organisms. Alterations in the diversity of the bacterial elements of the intestinal microbiota have been demonstrated with IBD. ${ }^{15,16}$

\section{Epidemiology of IBD}

Around one-quarter of individuals with IBD are diagnosed in the first 20 years of life. ${ }^{17,18}$ Of those diagnosed within these 2 decades, most are diagnosed in adolescence, with rates increasing from early in the second decade of life. ${ }^{3}$ In addition, reports from different countries demonstrate increasing rates of IBD, especially in adolescence. ${ }^{3,19,20}$ Studies conducted in Australia show that the incidences of both $\mathrm{CD}^{21}$ and $\mathrm{UC}^{22}$ have increased more than ten-fold in pediatric populations during recent decades. The reasons for the observed changes in incidence are unclear, but they may reflect changes in lifestyle, diet, urbanization, or other environmental changes.

\section{Presentation patterns of IBD in adolescents}

Although adolescents with IBD may present with a wide range of symptoms, particular features unique to this age group are poor linear growth and delayed pubertal development. The classical presentation of CD in children and adolescence comprises pain, diarrhea, and weight loss, while UC presents most commonly with bloody diarrhea. ${ }^{1,23}$ Adolescents may also present with a range of atypical symptoms. These may include other gastrointestinal complaints, such as lip swelling and oral ulceration. ${ }^{2,23}$ Extra-intestinal manifestations (EIM) of IBD can also be present at diagnosis. ${ }^{24,25}$ EIMs include axial or peripheral arthritis, skin rashes (eg, erythema nodosum), and eye diseases (eg, uveitis). The presence of less classical symptoms may delay recognition and diagnosis, while also increasing morbidity and distress, and compromising growth further.

\section{The psychosocial impact of IBD in adolescents}

Numerous factors may impact on the psychological wellbeing of young people with IBD. These include unpredictable, unpleasant, and embarrassing symptoms; complex, 
demanding treatment regimens; treatment-related side effects; the ever-looming threat of exacerbations of the disease; and the requirement for "mutilating" surgical procedures., $46-28$ In particular, "ostomy" surgery is associated with issues of body image, feelings of body intrusion, additional challenges in gaining independence, and secrecy issues relating to the stoma. ${ }^{29}$ Adolescents with IBD frequently describe themes of discomfort and vulnerability, viewing themselves as different, and loss of control over their lives and futures. ${ }^{30}$

A number of studies have suggested that young people with IBD experience a significantly higher prevalence of psychiatric disorders, compared with healthy controls. ${ }^{31-35}$ Adolescents with IBD demonstrate higher levels of internalizing disorders (anxiety and depression). ${ }^{33-36}$ The rate of depression may be as high as $25 \%$; it is often under-recognized both by parents and health care professionals. The rate of depression in young people with IBD is at least equal to that seen in adolescents with other chronic diseases, including diabetes, cystic fibrosis, and non-organic abdominal pain. ${ }^{31,37-39}$ There is also a high prevalence of externalization (behavioral disorders), particularly in adolescent boys with IBD. ${ }^{33,35}$ These problems are characterized by increased aggression, communication difficulties, and withdrawal behavior.

These psychosocial challenges may have wide-ranging implications for the life of the adolescent with IBD. There is a higher reported rate of school absenteeism, less ability and inclination to socialize with peers, and lower levels of self-confidence in flirtation and establishing romantic relationships. ${ }^{40}$ Engstrom et $\mathrm{al}^{35}$ reported lower levels of self-esteem in adolescents with IBD, although other studies have failed to demonstrate any difference from healthy controls. ${ }^{32}$ There is a tendency for young people with IBD to demonstrate higher levels of avoidance behavior. ${ }^{28}$ The development of peer relationships and autonomy also may be compromised, ${ }^{41}$ along with greater tendency developed towards seeking emotional support from family members, rather than peers. ${ }^{42}$ This may lead to delays in emotional maturation and establishment of autonomy from parents and the social circle of the immediate family.

\section{Quality of life in adolescents with IBD}

The World Health Organization defines health-related quality of life (QOL) (HRQOL) as "an individual's perception of their position in life in the context of the culture and value systems in which they live and in relation to their goals, expectations, standards and concerns". ${ }^{43}$ There are increasing data that indicate the considerable impact of the psychosocial challenges imposed by a diagnosis of IBD on the QOL of young people with IBD.

Adler et $\mathrm{al}^{44}$ reported lower QOL in college students with IBD, and poorer adjustment to college life, compared with healthy peers. Adolescents with IBD appear to have greater impairments of QOL than younger children. ${ }^{45}$ There are gender differences in reported effects on QOL. Adolescent males are more focused on the effects of IBD on strength, and growth delay, whereas adolescent females appear to be more concerned by the effects on weight, self-image, and relationships. ${ }^{30,41,46}$ In one study, adolescent males were reported to experience adverse effects on emotional and physical well-being, as well as on family functioning. ${ }^{47}$ By contrast, adolescent females in this study experienced only negative impact on family functioning. ${ }^{47}$ The effects on HRQOL in adolescent males may be attributed to greater levels of anxiety and depression. These internalizing symptoms, which may be related to the unpredictable nature of IBD, have been shown to have strong correlation with HRQOL. ${ }^{33}$ Higher levels of externalizing symptoms are also associated with reduced QOL. ${ }^{48}$

A number of studies have demonstrated correlation between disease activity and HRQOL; ${ }^{30,41,45,48-51}$ but, other studies have failed to confirm this relationship. ${ }^{42}$ It seems likely that any proportion of the variance in HRQOL directly related to disease activity is small. ${ }^{49}$ By contrast, it is interesting to note that there appears to be a welldescribed association between functional symptoms and reduced QOL in adults with IBD. ${ }^{52}$ Coexistent functional symptomatology is well-recognized in patients with IBD. Up to two-thirds of individuals with $\mathrm{CD}$, and one-third of people with UC, experience symptoms of irritable bowel syndrome. ${ }^{52}$ Although there are no studies that directly assess the impacts of such symptoms upon QOL, functional symptoms are associated with higher rates of anxiety in children with IBD. ${ }^{53}$

Chronic illness demands more sophisticated coping strategies for the adolescent with IBD than the day-to-day challenges of life experienced by their healthy peers. MacPhee et $\mathrm{al}^{42}$ have suggested that young people with IBD often rely on their parents' abilities to cope. Consequently, there is a negative impact on HRQOL, if the family utilizes ineffective or maladaptive coping mechanisms. Protective factors for QOL have been identified for adolescents with IBD. These include: a greater degree of intimacy, satisfaction with social support networks, and familial positive coping strategies. ${ }^{42}$ In adolescents, a positive outlook has been shown to be associated with greater QOL. ${ }^{50}$ 
An understanding of the risk factors associated with reduced QOL, and the protective factors that ameliorate the effects of disease on HRQOL, may guide health care professionals in addressing these issues. As well as optimal medical management of the disease process, to limit the burden of disease symptomatology, a more holistic approach to care is required.

The literature on adults suggests that direct management of the psychiatric morbidity experienced by individuals with IBD is associated with an increased QOL. ${ }^{52}$ A pilot, twelve-week study of cognitive behavioral therapy in adolescents with IBD led to a reported reduction in depressive symptoms, although direct effects on overall QOL were not measured.${ }^{54}$ In addition, a broader approach of therapeutic maneuvers, to support families in developing effective coping mechanisms, may well be beneficial to improve QOL in adolescent patients.

\section{Medical management of IBD in adolescents}

In general, the medical management of both $\mathrm{CD}$ and $\mathrm{UC}$ in adolescence comprises specific drugs to induce remission, followed by other therapies to ensure maintenance of remission. The various therapeutic options need to be considered within the context of the individual patient, their individual disease pattern, disease complications, and the availability of the specific therapy. The potential risks of side effects for any specific therapy need to be balanced with the expected benefits. Candid and open discussions with the adolescent patient and their parents will often be required.

The drug therapies utilized to induce remission in active CD include: corticosteroids (CS), antibiotics, and biological therapies. Corticosteroids have long been considered the principal therapy for active $\mathrm{CD}$, and continue to be widely used in some centers. Although CS may improve symptoms, there is increasing recognition that they lead to relatively low rates of mucosal healing, and have unacceptable side effect profiles, especially for adolescents. ${ }^{5,55}$ Although budesonide has substantially fewer systemic side effects than oral prednisone, it has also less efficacy, and it appears to have optimal benefits only for terminal ileal CD. ${ }^{55}$

Metronidazole, separately or in combination with ciprofloxacin, may have roles in the management of mildly active luminal $\mathrm{CD}$, and perianal and perioral diseases. ${ }^{56}$ These antibiotics may also have roles in the management of disease flares, as alternatives to corticosteroids..$^{57}$

Biological therapies have clear roles in the induction of remission in severe $\mathrm{CD}$, and in the subsequent maintenance of disease, with ongoing dosing. The efficacy and safety of both infliximab ${ }^{58}$ and adalimumab ${ }^{59}$ have been considered in children and adolescents. Although concerns remain about potential side effects, the significant benefits, in terms of achieving remission, high rates of mucosal healing, and enhancing growth need to be considered strongly, in an adolescent with severe disease complicated by growth failure and/or pubertal delay. Although there is developing evidence to support the early introduction of these drugs (the top-down approach) ${ }^{60}$ this is limited in many areas (such as, New Zealand and Australia) by access requirements. ${ }^{61}$

After the establishment of remission, the key goal of ongoing management in adolescents with $\mathrm{CD}$ is maintenance of remission (preventing relapse). CS and antibiotics do not have roles in the maintenance of remission, and the 5-aminosalicylates (eg, mesalazine) have only a limited role. ${ }^{56}$ By contrast, immunosuppressive drugs have defined roles in the maintenance of remission of $\mathrm{CD}$ in adolescence. Thiopurines (azathioprine or 6-mercaptopurine) are typically used first, with methotrexate tending to be used in settings of thiopurine failure or intolerance. ${ }^{62}$ Early use of thiopurines in moderate-severe disease is shown to lead to less requirement for CS, more prolonged remission, and better growth. ${ }^{63}$ However, both thiopurines and methotrexate are associated with various side effects, including bone marrow suppression, hepatotoxicity, and increased sun sensitivity. The thiopurines are also linked with idiopathic pancreatitis, typically leading to vomiting and epigastric pain during the first 7-10 days after initiation. Monitoring of the thiopurine metabolites (6-thioguanine nucleotide and 6-methyl mercaptopurine) can help in optimizing dosing, preventing adverse effects, and indicating poor adherence. ${ }^{64}$ Biologic drugs, if used successfully to induce remission, can be continued as maintenance therapy in standard regimens. ${ }^{65}$

Therapies to induce remission in active UC include CS and 5-aminosalicylic acid (5-ASA) agents. Adolescents with acute severe colitis (ASC) will usually require intravenous $\mathrm{CS}$, with consideration for rescue therapy if there is no response. Medical therapies for failed CS in ASC include cyclosporine or tacrolimus, ${ }^{66}$ or a biological drug. ${ }^{67,68}$ Adolescents who fail medical therapy will require colectomy in this instance.

The 5-ASA drugs tend to be the mainstay in maintenance of remission. ${ }^{69}$ These medications can be delivered orally or rectally (however, this route is often not favored by adolescents). Although numerous studies support the early introduction of thiopurines in moderate-severe $\mathrm{CD}$, there is less data in UC. Recently, a prospective multicenter study 
evaluated the outcomes of thiopurines in UC in 394 children and adolescents recruited at diagnosis. ${ }^{70}$ Of this group, 197 patients received thiopurines (half within the first 3 months of diagnosis). Of the 133 patients re-evaluated after 12 months, 65 were in remission, without CS or other therapy.

Methotrexate may have a role when UC is unresponsive to a thiopurine, or when there is intolerance, but this is currently supported only by limited controlled case series data. ${ }^{57,71}$ Other drugs (such as thalidomide, tacrolimus, or mycophenylate) may play a role in the maintenance of remission, but the data supporting these is less clear. ${ }^{57}$

A recent report demonstrated the benefits of infliximab in pediatric UC. ${ }^{68}$ The outcomes of 52 prospectively recruited children and adolescents were followed for a median of 30 months. CS-free remission was seen in 38\% of these children at 12 months, with $21 \%$ in remission after 24 months. After 2 years of follow-up, 39\% of this group had undergone colectomy. An Italian study group has also reviewed their experience with infliximab in children and adolescents with UC. ${ }^{72}$ These 22 patients had been treated with infliximab using a three-dose induction course and ongoing maintenance dosing (8-weekly). Some of the group had acute severe colitis with no response to $\mathrm{CS}$, while others had a protracted course with/without CS dependency. Overall, twelve of the 22 subjects had full response, with CS-free remission after 12 months, and six others had partial response. Seven subjects required colectomy (only one during the acute period).

In addition to the standard medical therapies, a number of other therapies may be considered by adolescents and their parents. Fish oils ${ }^{73}$ and probiotics ${ }^{74}$ may play adjunctive roles, particularly in UC. Adolescents and/or their parents may consider one or more complementary or alternative medication (CAM) agents. Given that CAM agents are commonly used in adolescent IBD populations, ${ }^{75}$ practitioners should be aware of this and remember to ask carefully about CAM usage.

\section{Surgical management of IBD in adolescents}

A number of adolescents with IBD will require surgical intervention within the first years after diagnosis. The cumulative rate of surgery in one series of 404 children and adolescents with CD was $20 \%$ at 3 years, and $34 \%$ at 5 years. ${ }^{10}$ Surgery for $\mathrm{CD}$ is not considered curative; surgery is often focused upon managing a disease complication. Specific indications include the management of perianal disease, resection of disease unresponsive to medical therapy, and resection of fibrotic strictures. When luminal disease is unresponsive to medical therapies, surgery that involves a defunctioning procedure (or a limited resection) might permit relief from symptoms and resumption of normal growth patterns. However, the risks and benefits of such an intervention need to be carefully discussed with the adolescent and their family. A period of 1-2 weeks hospital stay for a surgical procedure, and a further period of convalescence at home before returning full time to school, may be a reasonable option in a teenager with very disabling CD preventing school attendance, limiting social interaction and interrupting growth.

In adolescents with UC the indications for colectomy include: ASC unresponsive to medical therapy, severe colitis complicated by toxic megacolon and/or perforation, intractable chronic colitis unresponsive to medical therapies and also following the finding of precancerous changes. Although colectomy in an adolescent with UC will remove the complete focus of disease, there remain concerns about subsequent issues, such as pouchitis, and altered fertility. Newby et $\mathrm{al}^{8}$ reported that $17.6 \%$ of 72 children with UC underwent one or more major operations over the period of study, with a mean time of 1.92 years to the first procedure.

\section{Management of nutrition and nutritional therapy in adolescents with IBD}

Almost all adolescents with $\mathrm{CD}$, and many with $\mathrm{UC}$, have concerns about poor weight gain, impaired linear growth, or delayed puberty, at diagnosis or subsequently. ${ }^{2,76,77}$ Poor weight gain typically results from reduced oral intake, due to anorexia, early satiety, nausea, or pain. Impaired linear growth reflects nutritional impairment. The systemic circulation of proinflammatory cytokines, such as interleukin 6, in particular, modulates the activity of key mediators of growth, especially insulin-like growth factor 1, thereby affecting growth hormone activity, while also altering growth plate responses. $^{78}$

In addition, active IBD can adversely affect pubertal development in adolescents, especially in males with CD. ${ }^{76}$ Failure to adequately control active disease during these crucial years may lead to significant consequences upon pubertal growth, leading ultimately to reduced final height acquisition. ${ }^{79,80}$

Consequently, assessment of growth and pubertal status at diagnosis of IBD in an adolescent, along with ongoing close monitoring of growth parameters throughout adolescence, is an essential aspect of monitoring. Nutritional interventions are often required in adolescents, especially those with CD. These include supplementary enteral nutrition, to enhance caloric intake and maintain remission, and exclusive enteral 
nutrition $(\mathrm{EEN})$, to induce or reinduce remission in active CD. ${ }^{81}$ EEN comprises the provision of a complete liquid diet, along with exclusion of standard dietary components. It should be considered the preferred and optimal therapy to induce remission in adolescent $\mathrm{CD}$, due to its combination of high efficacy and low adverse effect profile. ${ }^{82,83}$ EEN protocols and utility have been considered in recent reviews of this therapy in pediatric and adolescent CD. ${ }^{82,83}$

Typically, EEN is delivered over a period of up to 8 weeks, with regular support, including dietetic and medical review during this time, to ensure that the adolescent is responding adequately, as well as coping psychologically with the absence of solid food in the diet. ${ }^{84}$ Socially, the absence of food can be stigmatizing during this period, and support from health professionals during this period is vital. Key medical assessments include review of adherence, tolerance of the formula, weight, symptoms, and inflammatory markers. At completion of the period of EEN, normal diet is slowly reintroduced over 7-10 days, with one meal introduced every 3-4 days, along with concurrent reductions in volume of formula..$^{83}$

EEN is able to induce remission in $80 \%-85 \%$ of children and adolescents with active $\mathrm{CD}$, in most published data, but does not have a role in UC. One meta-analysis of pediatric studies suggested that EEN was equivalent to $\mathrm{CS}$ in induction of remission. ${ }^{85}$ By contrast, a Cochrane review has concluded that CS is superior to EEN. However, this included mainly studies of adult subjects, treated with EEN. ${ }^{86}$ The outcomes and consequences appear to be different in adult patients with CD than in children and adolescents, with the majority of patients in pediatric studies being in the adolescent age group. The reasons for the differences between responses in adolescents and adults are unclear, but may include disease duration, adherence to therapy, and comorbidities.

In addition to inducing remission, EEN is one of the few current medical therapies recognized to promote high rates of mucosal healing. Borelli and colleagues ${ }^{87}$ reported that $74 \%$ of a group of 19 children who were managed with EEN had mucosal healing afterwards. This contrasts with the rate of $33 \%$ in a comparison group treated with CS to induce remission. An earlier, Italian study demonstrated mucosal improvements in $70 \%$ of a group treated with EEN, and $40 \%$ of subjects treated with corticosteroids. ${ }^{88}$

EEN has been shown to yield prompt and significant improvements in nutrition, which include early changes in levels of insulin-like growth factor 1, along with improvements in growth parameters. ${ }^{76,83}$ EEN also improves bone nutrition, with rapid improvements in markers of bone turnover consequent to EEN therapy. ${ }^{89}$ In addition to the short-term benefits of EEN, the initial use of EEN has a number of advantages that persist long beyond the initial period of EEN itself. ${ }^{88,90,91}$ These include more sustained remission and better growth, compared with those treated initially with CS.

There are not yet clear ways to guide the individualization of the length of EEN for each patient. Establishing the rate at which specific inflammatory markers improve may be a potential mechanism to guide the length of therapy. Gerasimidis and colleagues ${ }^{92}$ demonstrated that a reduction of calprotectin of $>18 \%$, after 30 days of EEN, predicted a clinical response within 8 weeks of therapy. Focused evaluations of EEN, over different time periods, are clearly required. These should be linked with studies that consider how best to evaluate responses to EEN, to be able to predict those who will require a longer duration, as against those who will have a clear induction of remission in a shorter time period.

\section{Adherence to therapy in adolescents with IBD}

Successful management of IBD is almost universally dependent on the use of long-term maintenance therapies. Similar to other pediatric chronic diseases, nonadherence rates vary between $38 \%-66 \%$ in children and adolescents with IBD. ${ }^{27,64,93-95}$ Furthermore, a number of studies document that adherence rates are lowest in adolescents. ${ }^{96-99}$

The reasons for poor adherence to medication are multiple. IBD is often diagnosed in adolescence, which is a time characterized by a greater desire for autonomy. ${ }^{100}$ This may lead to delegation to the young person of responsibility for medication adherence, rather than direct supervision by a parent. ${ }^{93}$ Barriers to adherence for the young person may include remembering to take their medication, and the need to set aside time to take medication. Both children and their parents cite lack of time as the most common barrier to adherence. ${ }^{101}$

A further challenge to adherence relates to the lack of immediate benefit to be derived from taking medication. It is recognized, in other conditions, that medication adherence rates are lower when diseases are in remission. ${ }^{102,103}$ Although adolescence is a developmental stage, which is characterized by a transition from short-term thinking to long-term thinking, the timing of this is variable; adolescents' motivations for action often relate to short-term consequences, rather than long-term health benefits. It may be difficult for the young person to perceive the benefits of taking the medication, especially as long-term adherence is required to maintain 
remission, even when the young person feels entirely well. Furthermore, exacerbations of disease may occur, even in the context of excellent adherence. ${ }^{101}$ This may reinforce a sense of uncertainty, or even of futility, surrounding the value of adherence to treatment. Limited knowledge of the disease may mean also that young people may fail to recognize the consequences of nonadherence.

Adolescence is characterized also by a desire to "fit in", and to be viewed not as different from peers. ${ }^{100}$ The socially-embarrassing nature of the disease, and the need to take regular medication, may automatically identify a young person with IBD as different, which may contribute to poor adherence. Furthermore, side effects of medication may provide significant barriers to adherence. ${ }^{101,104}$ These include visible effects, such as steroid-related effects on appearance (with associated impact on body image and self-esteem), as well as fears related to other side effects of treatment.

IBD treatment often involves complex drug therapies, involving multiple medications and frequent dosing. An early study of medication adherence in adults demonstrated that a greater number of medications and greater frequency of dosing were associated with reduced adherence. ${ }^{105}$ However, other studies have failed to confirm this finding, with some studies suggesting that a greater number of daily doses was associated with improved adherence. ${ }^{106-109}$ In a recent study of adherence in adolescents with IBD, patients identified increased complexity of medication regimen as a barrier to adherence. ${ }^{101}$ Specifically, adolescents on monotherapy reported significantly fewer barriers to adherence than those on multiple medications.

Various risk factors for nonadherence in the adolescent population have been described. Family dysfunction, including poor family structure, cohesion, and child discipline has been associated with poor adherence in several studies. ${ }^{93,95}$ Lower income and minority status have been linked to poorer adherence in some, but not all studies. ${ }^{95}$ It has been suggested also that poor coping strategies may be related to reduced adherence, though there are limited data to support this theory. ${ }^{95}$ Finally, psychological stressors, including depression and low self-esteem, are associated with poor adherence in adolescents with various chronic health conditions. ${ }^{95,110,111}$

Although adherence to medical therapy is crucial to optimizing outcomes, assessment of nonadherence is extremely challenging. Clinician estimates of adherence are notoriously inaccurate. ${ }^{112,113}$ Self reports and parental reports tend to overestimate adherence..$^{95}$ Medication measurement techniques, such as assessment of repeat prescriptions or counting pills, do not provide any guarantee that the medication has actually been taken. Even more objective measurements, such as drug levels, may be limited by variable pharmacokinetics, lack of correlation between levels and clinical efficacy, and the problem that, for many medicines, these levels are a reflection only of recent consumption, rather than long-term adherence. ${ }^{4,103}$

Strategies that improve adherence should lead to better disease control and reduction in disease-related complications. The optimal nature of such strategies remains unclear, but is likely to be multifaceted. This may involve rationalization of treatment regimens; adoption of strategies to organize medication (eg, pill boxes, utilization of electronic reminders, supplies of medication at home and school, etc), patient education, encouraging appropriate and effective development of autonomy, and measures to address psychological and social risk factors for poor adherence.

\section{Monitoring progress in adolescents with IBD}

Although clinical assessment (symptom review) remains important in adolescents with IBD, consideration of biochemical monitoring, growth review, and assessment of mucosal healing are also important components. Regular review of symptoms (both gastrointestinal and extraintestinal) and growth measurement are critical. Regular review of adherence is also important.

Regular estimation of inflammatory markers, full blood count, and liver chemistry (every 3 months, in any adolescent on an immunosuppressive drug) along with annual monitoring of absorptive markers (eg, vitamins D and B12, folate, iron) is appropriate. Annual bone age estimation (x-ray of left wrist), from diagnosis and annually through adolescence, is helpful in delineating growth and skeletal development in CD (Table 1). ${ }^{114}$

As noted earlier, achieving mucosal healing is increasingly important, given the impact that it has on the subsequent course of disease. ${ }^{115} \mathrm{~A}$ dilemma remains as to the best way to assess mucosal healing. The use of noninvasive markers, such as calprotectin, is advancing. ${ }^{116,117}$ However, the optimal level to aim for, and the frequency of appropriate measurement, remain unclear. The precise role for fecal calprotectin and/ or other noninvasive markers will hopefully become more clear in the coming years.

In addition to the above assessments, an adolescentfocused history is also important; it provides an understanding of the impact of the underlying disease upon the psychological state of the adolescent. This can be facilitated by the use of the HEADSS assessment, which involves asking 
Table I Annual monitoring tests in adolescents with inflammatory bowel disease

\begin{tabular}{ll}
\hline Measure & Note \\
\hline Full blood count & \\
Liver chemistry & \\
Urea, creatinine and electrolytes & \\
Erythrocyte sedimentation rate & \\
C-reactive protein & \\
Vitamin D & \\
Vitamin BI2 & \\
Folate & \\
Iron & \\
Calcium, magnesium, phosphate & If relevant \\
Thiopurine metabolites & X-ray left wrist \\
(6-thioguanine and 6-mercaptopurine) & May be indicated by history \\
Bone age & of recurrent fractures, severe \\
Bone densitometry & malnutrition, or prolonged \\
& corticosteroid exposure \\
& \\
Review of pubertal status & \\
Review of immunization status & \\
Dietetic review & \\
Psychology review & \\
Transition planning & \\
\hline
\end{tabular}

Note: Although some monitoring will be specific to individuals patients (reflecting particular medical therapies), a number of monitoring steps should be conducted at least annually in all adolescents.

about key aspects of an adolescent's life, covering areas such as home, education, activities, employment, drugs, suicidality, sex, and safety. ${ }^{18,119}$

\section{Transition of adolescents with IBD to adult services}

Over the past decade, there has been increasing recognition of the importance of effectively supporting the adolescent with chronic disease in making a transition from care within a pediatric setting, to the adult clinic. There is a danger that these adolescents may not have their needs fully met, either in the family-centered, developmentally-focused pediatric setting (which does not acknowledge their growing independence), or in the adult medical clinic (which acknowledges patient autonomy, reproduction, and employment issues, but may not recognize growth, development, and family issues). ${ }^{120}$ There is an imperative for clinicians who care for adolescents to understand and address their developmental, psychological, and educational needs, rather than solely their medical care.

The potential adverse effects of poorly managed transition are well documented in many patient groups, including effects on health (for example, worsening glycemic control in patients with diabetes mellitus, ${ }^{121-124}$ graft failure in transplant recipients), ${ }^{125,126}$ and health service use (increased loss to follow-up, with poorer health outcomes in some cases, for survivors of childhood cancer ${ }^{127}$ and cardiac surgery). ${ }^{128}$ Literature that directly addresses the adverse health effects of poorly managed transition in IBD is relatively scarce. However, a recent study by Bollegala et al ${ }^{129}$ identified a significant reduction in outpatient clinic visit frequency, and an increase in documented nonadherence, after transfer to adult care.

Furthermore, the phenotype of childhood-onset IBD is of more severe disease, with a greater potential for complications..$^{910}$ A case control study of 100 adolescents with IBD, compared against adults with disease of equal duration, demonstrated a higher rate of hospital admission, higher immunosuppressant use, and a greater requirement for biological therapy in the adolescent group. ${ }^{130}$ Therefore, the potential for poorer outcomes and worsening quality of life is huge, if transition to adult care is poorly managed. However, within the IBD community, the importance of effective transition has yet to be universally recognized, and comprehensive transition services for young people with IBD are still uncommon.

Multiple guidelines have been proposed by national medical societies that provide consensus guidance on transitioning adolescents with chronic illness, or IBD, specifically. ${ }^{131-135}$ However, a single optimal model of transitional care has not been described, and no single model of care will fit all cases, for individual adolescents, clinicians, and institutions. Any transition program must recognize the medical, psychological, social, and educational needs of young people as they move from a child-centered to an adult-oriented health care system. A survey of adult gastroenterologists in the USA reported $73 \%$ competence in managing medical aspects of adolescent care, but only $46 \%$ competence with developmental and mental health issues. ${ }^{136}$ Although the perfect "one size fits all" transition program does not exist, minimal requirements for a transition program can be identified. ${ }^{137}$

Some of the key requirements for transition programs include having a transition policy, active involvement of both adolescent and adult personnel, structured pathways through the transition process (but with flexibility to suit individual needs), addressing knowledge needs of the young adults, and broad, multidisciplinary inputs, whilst also addressing disease-specific care, and generic health education and skills training for young people. It is also important that transition programs address the needs of the parents and families in the move from pediatric to adult care. Although the ultimate aim of transition is to empower the adolescent to gain autonomy and responsibility for their care, this is likely to be 
a gradual process. It is important to acknowledge the role that parents have played and may continue to play in care.

Several newly-developed tools may prove useful in guiding adolescents through a transition pathway. For example, the Inflammatory Bowel Disease Knowledge Inventory Device (IBD-KID) has been developed and validated as a tool to assess disease-specific knowledge in the adolescent age group. ${ }^{138}$ The outcomes of this assessment can then be used to focus additional educational activities. This device has been included in the authors' transition program, but is yet to be formally assessed in this role. Zijlstra et $\mathrm{al}^{139}$ have recently developed the IBD-yourself questionnaire, which was designed to assess self-efficacy in adolescents, as a component of readiness for transition. In addition, a Canadian study developed a tool to highlight knowledge gaps in adolescents proceeding through a transition program. ${ }^{140}$

Overall, it is important that young people are involved in the development of transition programs, and in the individualization of their own transition to adult care. This will enhance their sense of control and autonomy. Transition is a major life event for young people with chronic illness. ${ }^{120}$ Although there are limited data to demonstrate improved outcomes related to effective transition in IBD, there is evidence that effective transition may be related to improved health outcomes and service utilization in other chronic conditions. ${ }^{141}$ Furthermore, there is good evidence of adverse effects related to poorly managed transition to adult care. ${ }^{129}$ Therefore, the provision of transition services for adolescents with IBD is essential for all centers involved in managing pediatric IBD. However, further research is required to evaluate optimal design, health-related outcomes, and cost-effectiveness of these programs of care.

\section{Summary of overall principles of management of IBD in adolescents}

Given the various adverse impacts of this chronic disease, management of IBD in adolescents needs to have a broad perspective, with consideration of more than just medical therapies or surgical interventions. Additional, important key components of the management of IBD in adolescents include growth and nutrition, psychological effects, schooling/education, sports and social aspects, and the impact upon the wider family (Figure 1).

Consequent to these many and varied impacts, adolescents with IBD should be managed within a multidisciplinary team, with individual practitioners able to provide expertise and experience across these spheres. Furthermore, these various

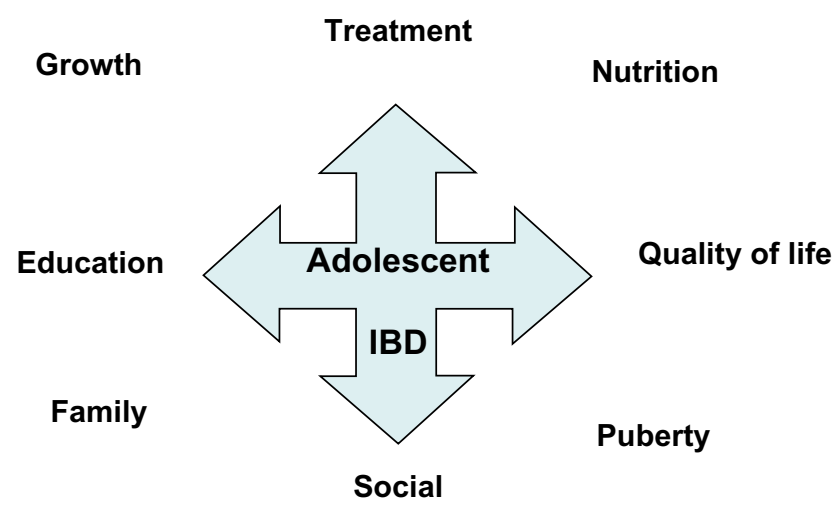

Figure I Multiple aspects of management of IBD in adolescents. Note: Reflecting the many and varied potential adverse impacts of IBD in adolescents, the management of this chronic disease must be multidimensional.

Abbreviation: IBD, inflammatory bowel disease.

components all need to be delivered within a framework that is adolescent-friendly, holistic, and supportive, yet fostering independence and developing maturity.

General aspects of management for adolescents include having a good, well-balanced diet, encouraging regular exercise, good sleep, and managing stress. Lifestyle choices also need to be discussed with an adolescent; smoking should be avoided, while adolescents should be advised to be careful with alcohol exposure (especially with specific medications or with liver disease). Generally, one should encourage the concept of "looking after your whole body, so it can look after your gut better".

\section{Conclusion}

The period of adolescence poses many challenges, especially for those young people diagnosed with IBD. Both CD and UC can have many and varied adverse impacts upon adolescents, especially with regard to nutrition, growth, and pubertal development. The management of IBD in this age group must take these important factors into account, with care being holistic and multidisciplinary.

\section{Disclosure}

The authors do not have any conflicts of interest relevant to this manuscript.

\section{References}

1. Ruemmele FM. Pediatric inflammatory bowel disease: coming of age. Curr Opin Gastroenterol. 2010;26(4):332-336.

2. Griffiths AM, Hugot J-P. Chapter 41, Crohn disease. In: Walker A, Goulet O, Kleinman RE, et al, editors. Pediatric Gastrointestinal Disease. 4th ed. Hamilton, ON, Canada: BC Decker; 2004.

3. Benchimol EI, Fortinsky KJ, Gozdyra P, et al. Epidemiology of pediatric inflammatory bowel disease: a systematic review of international trends. Inflamm Bowel Dis. 2011;17(1):423-439. 
4. Mamula P, Markowitz JE, Baldassano RN. Inflammatory bowel disease in early childhood and adolescence: special considerations. Gastroenterol Clin North Am. 2003;32(3):967-995, viii.

5. Cosnes J, Gower-Rousseau C, Seksik P, Cortot A. Epidemiology and natural history of inflammatory bowel diseases. Gastroenterology. 2011;140(6):1785-1794.

6. Geboes K, Colombel JF, Greenstein A, et al. Indeterminate colitis: a review of a concept - what's in a name? Inflamm Bowel Dis. 2008;14(6): $850-857$.

7. Feakins RM. Inflammatory bowel disease biopsies: British Society of Gastroenterology reporting guidelines. J Clin Pathol. September 25, 2013. doi: 10.1136/jclinpath-2013-201885. [Epub ahead of print.]

8. Newby EA, Croft NM, Green M, et al. Natural history of paediatric inflammatory bowel diseases over a 5-year follow-up: a retrospective review of data from the register of paediatric inflammatory bowel diseases. J Pediatr Gastroenterol Nutr. 2008;46(5):539-5345.

9. Van Limbergen J, Russell RK, Drummond HE, et al. Definition of phenotypic characteristics of childhood onset inflammatory bowel disease. Gastroenterology. 2008;135(4):1144-1122.

10. Vernier-Massouille G, Balde M, Salleron J, et al. Natural history of pediatric Crohn's disease: a population-based cohort study. Gastroenterology. 2008;135(4):1106-1113.

11. Lemberg DA, Clarkson C, Bohane T, Day AS. The role of esophago-gastro-duodenoscopy in the initial assessment of children with IBD. J Gastroenterol Hepatol. 2005;20(11):1696-1700.

12. Imielinski M, Baldassano RN, Griffiths A, et al. Common variants at five new loci associated with early onset inflammatory bowel disease. Nat Genet. 2009;4(12):1335-1340.

13. Franke A, McGovern DP, Barrett JC, et al. Genome-wide meta-analysis increases to 71 the number of confirmed Crohn's disease susceptibility loci. Nat Genet. 2010;42 (12):1118-1125.

14. Glocker EO, Kotlarz D, Boztug K, et al. Inflammatory bowel disease and mutations affecting the interleukin-10 receptor. $N$ Engl J Med. 2009;361(21):2033-2045

15. Man SM, Kaakoush NO, Mitchell HM. The role of bacteria and pattern-recognition receptors in Crohn's disease. Nat Rev Gastroenterol Hepatol. 2011;8(5):152-168.

16. Kaakoush NO, Day AS, Huinao KD, et al. Microbial dysbiosis in pediatric patients with Crohn's disease. J Clin Microbiol. 2012;50(10): 3258-3266.

17. Rogers BH, Clark LM, Kirsner JB. The epidemiologic and demographic characteristics of inflammatory bowel disease: an analysis of a computerized file of 1400 patients. J Chronic Dis. 1971;24(12):743-773.

18. Mir-Madjlessi SH, Michener WM, Farmer RG. Course and prognosis of idiopathic ulcerative proctosigmoiditis in young patients. $J$ Pediatr Gastroenterol Nutr. 1986;5(4):570-575.

19. Molodecky NA, Soon IS, Rabi DM, et al. Increasing incidence and prevalence of the inflammatory bowel diseases with time, based on systematic review. Gastroenterology. 2012;142(1):46-54.

20. Benchimol EI, Guttmann A, Griffiths AM, et al. Increasing incidence of pediatric inflammatory bowel disease in Ontario, Canada: evidence from health administrative data. Gut. 2009;58(11):1490-1497.

21. Phavichitr N, Cameron DJ, Catto-Smith AG. Increasing incidence of Crohn's disease in Victorian children. J Gastroenterol Hepatol. 2003;18(3):329-332.

22. Schildkraut V, Alex G, Cameron DJ, et al. Sixty-year study of incidence of childhood ulcerative colitis finds eleven-fold increase beginning in 1990s. Inflamm Bowel Dis. 2013;19(1):1-6.

23. Griffiths AM. Specificities of inflammatory bowel disease in childhood. Best Pract Res Clin Gastroenterol. 2004;18(3):509-523.

24. Greenstein AJ, Janowitz HD, Sacher DB. The extra-intestinal complications of Crohn's disease and ulcerative colitis: a study of 700 patients. Medicine. 1976;55(5):401-412.

25. Hyams JS. Extraintestinal manifestations of inflammatory bowel disease in children. J Pediatr Gastroenterol Nutr. 1994;19(1):7-21.

26. Dubinsky M. Special issues in pediatric inflammatory bowel disease. World J Gastroenterol. 2008;14(3):413-420.
27. Hommel KA, Davis CM, Baldassano RN. Medication adherence and quality of life in pediatric inflammatory bowel disease. $J$ Pediatr Psychol. 2008;33(8):864-874.

28. Loonen HJ, Derkx BH, Griffiths AM. Pediatricians overestimate importance of physical symptoms upon children's health concerns. Med Care. 2002;40(10): 996-1001.

29. Nicholas DB, Swan SR, Gerstle TJ, et al. Struggles, strengths, and strategies: an ethnographic study exploring the experiences of adolescents living with an ostomy. Health Qual Life Outcomes. 2008;6:114.

30. Nicholas DB, Otley A, Smith C, et al. Challenges and strategies of children and adolescents with inflammatory bowel disease: a qualitative examination. Health Qual Life Outcomes. 2007;5:28.

31. Engstrom I. Inflammatory bowel disease in children and adolescents: Mental health and family functioning. J Pediatr Gastroenterol Nutr. 1999;28(4):S28-S33.

32. Vaisto T, Aronen ET, Simola P, et al. Psychosocial symptoms and competence among adolescents with inflammatory bowel disease and their peers. Inflamm Bowel Dis. 2010;16(1):27-35.

33. De Boer M, Grootenhuis M, Derkx B, et al. Health-related quality of life and psychosocial functioning of adolescents with inflammatory bowel disease. Inflamm Bowel Dis. 2005;11(4):400-406.

34. Mackner LM, Crandall WV, Szigethy EM. Psychosocial functioning in pediatric inflammatory bowel disease. Inflamm Bowel Dis. 2006;12(3): 239-244.

35. Engstrom I. Mental health and psychological functioning in children and adolescents with inflammatory bowel disease: a comparison with children having other chronic illnesses and with healthy children. JChild Psychol Psychiatry. 1992;33(3):563-582.

36. Engstrom I, Lindquist BL. Inflammatory bowel disease in children and adolescents: a somatic and psychiatric investigation. Acta Paediatr Scand. 1991;80(6-7):640-647.

37. Burke P, Meyer V, Kocoshis S, et al. Depression and anxiety in pediatric inflammatory bowel disease and cystic fibrosis. $\mathrm{J} \mathrm{Am} \mathrm{Acad} \mathrm{Child}$ Adolesc Psychiatry. 1989;28(6):948-951.

38. Burke P, Kocoshis SA, Chandra R, et al. Determinants of depression in recent onset pediatric inflammatory bowel disease. J Am Acad Child Adolesc Psychiatry. 1990;29(4):608-610.

39. Raymer D, Weininger O, Hamilton JR. Psychological problems in children with abdominal pain. Lancet. 1984;1(8374):439-440.

40. Calsbeek H, Rijken M, Bekkers MJ, et al. Social position of adolescents with chronic digestive disorders. Eur J Gastroenterol Hepatol. 2002;14(5):543-549.

41. van der Zaag-Loonen HJ, Grootenhuis MA, Last BF, Derkx HH. Coping strategies and quality of life of adolescents with inflammatory bowel disease. Qual Life Res. 2004;13(5):1011-1019.

42. MacPhee M, Hoffenberg EJ, FeranchukA. Quality-of-life factors in adolescent inflammatory bowel disease. Inflamm Bowel Dis. 1998;4(1): 6-11.

43. Study protocol for the World Health Organization project to develop a Quality of Life assessment instrument (WHOQOL). Qual Life Res. 1993;2(2):153-159.

44. Adler J, Raju S, Beveridge AS, et al. College adjustment in University of Michigan students with Crohn's and colitis. Inflamm Bowel Dis. 2008;14(9):1281-1286.

45. Otley AR, Griffiths AM, Hale S, et al. Health-related quality of life in the first year after diagnosis of pediatric inflammatory bowel disease. Inflamm Bowel Dis. 2006;12(8):684-691.

46. Mussell M, Bocker U, Nagel N, et al. Predictors of disease-related concerns and other aspects of health-related quality of life in outpatients with inflammatory bowel disease. Eur J Gastroenterol Hepatol. 2004;16(12):1273-1280.

47. Karwowski CA, Keljo D, Szigethy E. Strategies to improve quality of life in adolescents with inflammatory bowel disease. Inflamm Bowel Dis. 2009;15(11):1755-1764.

48. Gray WN, Denson LA, Baldassano RN, Hommell KA. Disease activity, behavioral dysfunction, and health-related quality of life in adolescents with inflammatory bowel disease. Inflamm Bowel Dis. 2011;17(7): $1581-1586$. 
49. Otley A, Smith C, Nicholas D, et al. The IMPACT questionnaire: a valid measure of health-related quality of life in pediatric inflammatory bowel disease. J Pediatr Gastroenterol Nutr. 2002;35(4):557-563.

50. Drossman DA, Patrick DL, Mitchell CM, Zagami EA, Appelbaum MI. Health-related quality of life in inflammatory bowel disease. Functional status and patient worries and concerns. Dig Dis Sci. 1989;34(9): 1379-1386.

51. Perrin JM, Kuhlthau K, Chughtai A, et al. Measuring quality of life in pediatric patients with inflammatory bowel disease: psychometric and clinical characteristics. J Pediatr Gastroenterol Nutr. 2008;46(2): 164-171.

52. Simren M, Axelsson J, Gillberg R, et al. Quality of life in inflammatory bowel disease in remission: the impact of IBS-like symptoms and associated factors. Am J Gastroenterol. 2002;97(2):389-396.

53. Faure C, Giguere L. Functional gastrointestinal disorders and visceral hypersensitivity in children and adolescents suffering from Crohn's disease. Inflamm Bowel Dis. 2008;14(11):1569-1574.

54. Szigethy E, Whitton SW, Levy-Warren A, et al. Cognitive-behavioral therapy for depression in adolescents with inflammatory bowel disease: a pilot study. J Am Acad Child Adolesc Psychiatry. 2004;43(12): 1469-1477.

55. Sidoroff M, Kolho K-L. Glucocorticoids in pediatric inflammatory bowel disease. Scand J Gastroenterol. 2012;47(7):745-750.

56. Kale-Pradhan PB, Zhao JJ, Palmer JR, Wilhelm SM. The role of antimicrobials in Crohn's disease. Exp Rev Gastroenterol Hepatol. 2013;7(3):281-288.

57. Day AS, Ledder O, Leach ST, Lemberg DA. Crohns and colitis in children and adolescents. World J Gastroenterol. 2012;18(41):5862-5869.

58. Hyams J, Crandall W, Kugathasan S, et al. Induction and maintenance infliximab therapy for the treatment of moderate-to-severe Crohn's disease in children. Gastroenterology. 2007;132(3):863-873.

59. Russell RK, Wilson ML, Loganathan S, et al. A British Society of Paediatric Gastroenterology, Hepatology and Nutrition survey of the effectiveness and safety of adalimumab in children with inflammatory bowel disease. Aliment Pharmacol Ther. 2011;33(8):946-953.

60. Walters TD, Kim M, Denson LA, et al. Comparative effectiveness of early therapy with anti-tumor necrosis factor- $\alpha$ vs an immunomodulator in children with Crohn's disease. Gastroenterology. 2013. doi: 10.1053/j. gastro.2013.10.027. [Epub ahead of print.]

61. Schultz M, Gearry R, Walmsley R, et al. New Zealand Society of Gastroenterology statement on the use of biological therapy in IBD. NZ Med J. 2010;123(1314):1314.

62. Boyle B, Mackner L, Ross C, et al. A single-center experience with methotrexate after thiopurine therapy in pediatric Crohn disease. J Pediatr Gastroenterol Nutr. 2010;51(6):714-717.

63. Punati J, Markowitz J, Lerer T, et al. Effect of early immunomodulator use in moderate to severe pediatric Crohn disease. Inflamm Bowel Dis. 2008;14(7):949-954.

64. Ooi CY, Bohane TD, Lee D, Naidoo D, Day AS. Thiopurine metabolite levels in pediatric inflammatory bowel disease. Aliment Pharmacol Ther. 2007;25(8):941-947.

65. Hyams J, Walters TD, Crandall W, et al. Safety and efficacy of maintenance infliximab therapy for moderate to severe Crohn's disease in children: REACH open-label extension. Curr Med Res Opin. 2011;27(3): 651662

66. Bousvaros A, Kirschner BS, Werlin SL, et al. Oral tacrolimus treatment of severe colitis in children. J Pediatr. 2000;137(6):794-799.

67. Yang LS, Alex G, Catto-Smith AG. The use of biologic agents in pediatric inflammatory bowel disease. Curr Opin Pediatr. 2012;24(5): 699-714.

68. Hyams JS, Lerer T, Griffiths A, et al. Outcome following infliximab therapy in ulcerative colitis. Am J Gastroenterol. 2010;105(6): 1430-1436.

69. Zeisler B, Lerer T, Markowitz J, et al. Outcome following aminosalicylate therapy in children newly diagnosed as having ulcerative colitis. $J$ Pediatr Gastroenterol Nutr. 2013;56(1):12-18.

70. Hyams JS, Lerer T, Mack D, et al. Outcome following thiopurine use in children with ulcerative colitis: a prospective multicenter registry study. Am J Gastroenterol. 2011;106(5):981-987.
71. Willot S, Noble A, Deslandres C. Methotrexate in the treatment of inflammatory bowel disease: An 8-year retrospective study in a Canadian pediatric IBD center. Inflamm Bowel Dis. 2011;17(12): 2521-2526.

72. Cucchiara S, Romeo E, Viola F, et al. Infliximab for pediatric ulcerative colitis: a retrospective Italian multicenter study. Dig Liver Dis. 2008;40(Suppl 2):S260-S264.

73. Turner D, Zlotkin SH, Shah PS, Griffiths AM. Omega 3 fatty acids (fish oil) for maintenance of remission in Crohn's disease. Cochrane Database Syst Rev. 2009;(1):CD006320.

74. Pham M, Lemberg DA, Day AS. Probiotics: sorting the evidence from the myths. Med J Australia. 2008;188(5):304-308.

75. Day AS. A review of the use of complementary and alternative medicines by children with inflammatory bowel disease. Front Pediatr. 2013;1:9.

76. Moeeni V, Day AS. Impact of inflammatory bowel disease upon growth in children and adolescents. ISRN Pediatr. 2011;2011:365712.

77. Thomas AG, Taylor F, Miller V. Dietary intake and nutritional treatment in childhood Crohn's disease. J Pediatr Gastroenterol Nutr. 1993;17(1): 75-81

78. Walters TD, Griffiths AM. Mechanisms of growth impairment in pediatric Crohn's disease. Nat Rev Gastroenterol Hepatol. 2009;6(9):513-523.

79. Ferguson A, Sedgwick DM. Juvenile onset inflammatory bowel disease: height and body mass index in adult life. BMJ. 1994;308 (6939): 1259-1263.

80. Ballinger AB, Savage MO, Sanderson IR. Delayed puberty associated with inflammatory bowel. Pediatr Res. 2003;53(2):205-210.

81. Day AS, Whitten KE, Sidler M, Lemberg DA. Systematic review: nutritional therapy in paediatric Crohn's disease. Aliment Pharmacol Ther. 2008;27(4):293-307.

82. Critch J, Day AS, Otley AR, King-Moore C, Teitelbaum JE, Shashidar H. Clinical report: the utilization of enteral nutrition for the control of intestinal inflammation in pediatric Crohn disease. J Pediatr Gastroenterol Nutr. 2012;54(4):298-305.

83. Day AS, Burgess L. Exclusive enteral nutrition and induction of remission of active Crohn disease in children. Exp Rev Clin Immunol. 2013;9(4):375-384

84. Day AS, Whitten KE, Lemberg DA, et al. Exclusive enteral feeding as primary therapy for Crohn's disease in Australian children and adolescents: a feasible and effective approach. J Gastroenterol Hepatol. 2006;21(10):1609-1614.

85. Heuschkel RB, Menache CC, Megerian JT, Baird AE. Enteral nutrition and corticosteroids in the treatment of acute Crohn's disease in children. J Pediatr Gastroenterol Nutr. 2000;31(1):8-15.

86. Zachos M, Tondeur M, Griffiths AM. Enteral nutritional therapy for induction of remission in Crohn's disease. Cochrane Database Syst Rev. 2007;CD000542.

87. Borrelli O, Cordischi L, Cirulli M, et al. Polymeric diet alone versus corticosteroids in the treatment of active pediatric Crohn's disease: a randomised controlled open-label trial. Clin Gastroenterol Hepatol. 2006;4(6):744-753.

88. Berni Canani R, Terrin G, Borrelli O, et al. Short- and long-term therapeutic efficacy of nutritional therapy and corticosteroids in paediatric Crohn's disease. Dig Liver Dis. 2006;38(6):381-387.

89. Whitten KE, Leach ST, Bohane TD, Woodhead HJ, Day AS. Effect of exclusive enteral nutrition on bone turnover in children with Crohn's disease. J Gastroenterol. 2010;45(4):399-405.

90. Lambert B, Lemberg DA, Leach ST, Day AS. Long term outcomes of nutritional management of Crohn's disease in children. Dig Dis Sci. 2012;57(8):2171-2177.

91. Knight C, El-Matary W, Spray C, Sandhu BK. Long-term outcome of nutritional therapy in paediatric Crohn's disease. Clin Nutr. 2005;24(5):775-779.

92. Gerasimidis K, Nikolaou CK, Edwards CA, McGrogan P. Serial fecal calprotectin changes in children with Crohn's disease on treatment with exclusive enteral nutrition: associations with disease activity, treatment response, and prediction of a clinical relapse. J Clin Gastroenterol. 2011;45(3):234-2349. 
93. Hommel KA, Davis CM, Baldassano RN. Objective versus subjective assessment of oral medication adherence in pediatric inflammatory bowel disease. Inflamm Bowel Dis. 2009;15(4):589-593.

94. Mackner LM, Crandall,WV. Oral medication adherence in pediatric inflammatory bowel disease. Inflamm Bowel Dis. 2005;11(11): 1006-1012.

95. Oliva-Hemker MM, Abadom V, Cuffari C, Thompson RE. Nonadherence with thiopurine immunomodulator and mesalamine medications in children with Crohn disease. J Pediatr Gastroenterol Nutr. 2007;44(2):180-184.

96. Rapoff MA. Adherence to Pediatric Medical Regimens. New York: Kluwer Academic; 1999.

97. Gavin LA, Wamboldt MZ, Sorokin N, et al. Treatment alliance and its association with family functioning, adherence, and medical outcome in adolescents with severe, chronic asthma. J Pediatr Psychol. 1999;24(4):355-365.

98. McQuaid EL, Kopel SJ, Klein RB, Fritz GK. Medication adherence in pediatric asthma: reasoning, responsibility, and behavior. J Pediatr Psychol. 2003;28(5):323-333.

99. Thiruchelvem D, Charach A, Schachar RJ. Moderators and mediators of long-term adherence to stimulant treatment in children with ADHD. J Am Acad Child Adolesc Psychiatry. 2001;40(8):922-927.

100. Holmbeck GN, Greenley RN, Franks EB. Developmental issues and considerations in research and practice. In: Kazdin AE and Weisz JP, editors. Evidence-Based Psychotherapy for Children and Adolescents. New York: Guilford Press; 2003. 21-41.

101. Greenley RN, Stephens M, Doughty A, Raboin T, Kugathasan S. Barriers to adherence among adolescents with inflammatory bowel disease. Inflamm Bowel Dis. 2009;16(1):36-41.

102. Logan D, Zelikovsky N, Labay L, Spergel J. The Illness Management Survey: identifying adolescents' perceptions of barriers to adherence. J Pediatr Psychol. 2003;28(6):383-392.

103. Matsui DM. Children's adherence to medication treatment. In: Drotar D, editor. Promoting Adherence to Medical Treatment in Chronic Childhood Illness. Mahwah, NJ: Lawrence Erlbaum Assoc; 2000. 135-152.

104. LaGreca AM, Bearman KJ. Adherence to pediatric treatment regimens. In: Roberts MC, editor. Handbook of Pediatric Psychology. 3rd ed. New York: Guilford Press; 2003. 119-140.

105. Greenberg RN. Overview of patient compliance with medication dosing: a literature review. Clin Ther. 1984;6(5):592-599.

106. Shalansky SJ, Levy AR. Effect of number of medications on cardiovascular therapy adherence. Ann Pharmacother. 2002;36(10):1532-1539.

107. Billups SJ, Malone DC, Carter BL. The relationship between drug therapy noncompliance and patient characteristics, health-related quality of life, and health care costs. Pharmacotherapy. 2000;20(8):941-949.

108. Monane M, Bohn RL, Gurwitz JH, et al. Noncompliance with congestive heart failure therapy in the elderly. Arch Intern Med. 1994;154(4): 433-437.

109. Sharkness CM, Snow DA. The patient's view of hypertension and compliance. Am J Prev Med. 1992;8(3):141-146.

110. Kennard BD, Stewart SM, Olvera R, et al. Nonadherence in adolescent oncology patients: preliminary data on psychological risk factors and relationships to outcome. J Clin Psychol Med Settings. 2004;11(1): 31-39.

111. Kovacs M, Goldston D, Obrosky DS, et al. Prevalence and predictors of pervasive noncompliance with medical treatment among youths with insulin-dependent diabetes mellitus. J Am Acad Child Adolesc Psychiatry. 1992;31(6):1112-1119.

112. Charney E, Bynum R, Eldredge D, et al. How well do patients take oral penicillin? A collaborative study in private practice. Pediatrics. 1967;40(2):188-195.

113. Finney JW, Hook RJ, Friman PC, et al. The overestimation of adherence to pediatric medical regimens. Child Health Care. 1993;22(4):297-304.

114. Gupta N, Lustig RH, Kohn MA, Vittinghoff E. Determination of bone age in pediatric patients with Crohn's disease should become part of routine care. Inflamm Bowel Dis. 2013;19(1):61-65.
115. Froslie K, Jahnsen J, Moum B, et al. Mucosal healing in inflammatory bowel disease: results from a Norwegian population-based cohort. Gastroenterology. 2007;133(2):412-422.

116. Judd TA, Day AS, Lemberg DA, Turner D, Leach ST. An update of faecal markers of inflammation in inflammatory bowel disease. J Gastroenterol Hepatol. 2011;26(10):1493-1499.

117. Sidler MA, Leach ST, Day AS. Fecal S100A12 and fecal calprotectin as noninvasive markers for inflammatory bowel disease in children. Inflamm Bowel Dis. 2008;14(3):359-366.

118. Goldenring J, Rosen D. Getting into adolescent heads. Contemp Pediatr. 1988;5:75-90.

119. Goldenring J, Rosen D. Getting into adolescent heads: an essential update. Contemp Pediatr. 2004;21:64.

120. Viner R. Transition from paediatric to adult care. Bridging the gaps or passing the buck? Arch Dis Child. 1999;81(3):271-275.

121. Ellemann K, Noertved Soerensen J, Pedersen L, Edsberg B, Andersen OO. Epidemiology and treatment of diabetic ketoacidosis in a community population. Diabetes Care. 1984;7(6):528-532.

122. Snorgaard O, Eskildsen P, Vadstrup S, Nerup J. Diabetic ketoacidosis in Denmark: epidemiology, incidence rates, precipitating factors and mortality rates. J Intern Med. 1989;226(4):223-228.

123. Thompson C, Cummings F, Chalmers J, et al. Abnormal insulin treatment behaviour: a major cause of ketoacidosis in the young adult. Diabet Med. 1995;12(5):429-432.

124. Pound N, Sturrock N, Jeffcoate W. Age-related changes in glycated haemoglobin in patients with insulin-dependent diabetes mellitus. Diabet Med. 1996;13(6):510-513.

125. Keith DS, Cantarovich M, Paraskevas S, et al. Recipient age and risk of chronic allograft nephropathy in primary deceased donor kidney transplant. Transpl Int 2006;19:649-656.

126. Watson AR. Non-compliance and transfer from pediatric to adult transplant unit. Pediatr Nephrol. 2000;14(6):469-472.

127. Oeffinger KC, Mertens AC, Hudson MM, et al. Health care of young adult survivors of childhood cancer: a report from the Childhood Cancer Survivor Study. Ann Fam Med. 2004;2(1):61-70.

128. Yeung E, Kay J, Roosevelt GE, Brandon M, Yetman AT. Lapse of care as a predictor for morbidity in adults with congenital heart disease. Int J Cardiol. 2008;125(1):62-65.

129. Bollegala N, Brill H, Marshall JK. Resource utilization during pediatric to adult transfer of care in IBD. J Crohns Colitis. 2013;7(2):e55-e60.

130. Goodhand J, Dawson R, Hefferon M, et al. Inflammatory bowel disease in young people: the case for transitional clinics. Inflamm Bowel Dis. 2010;16(6):947-952.

131. Blum RW, Garell D, Hodgman CH, et al. Transition from child-centered to adult health-care systems for adolescents with chronic conditions. A position paper of the Society for Adolescent Medicine. J Adolesc Health. 1993;14(7):570-576.

132. A consensus statement on health care transitions for young adults with special health care needs. Pediatrics. 2002;110(6 Pt 2):1304-1306.

133. Transition to adult care for youth with special health care needs. Paediatr Child Health. 2007;12(9):785-793.

134. Baldassano R, Ferry G, Griffiths A, et al. Transition of the patient with inflammatory bowel disease from pediatric to adult care: recommendations of the North American Society for Pediatric Gastroenterology, Hepatology and Nutrition. J Pediatr Gastroenterol Nutr. 2002;34(3): 245-248.

135. Leung Y, Heyman MB, Mahadevan U. Transitioning the adolescent inflammatory bowel disease patient: guidelines for the adult and pediatric gastroenterologist. Inflamm Bowel Dis. 2011;17(10):2169-2173.

136. Hait EJ, Barendse RM, Arnold JH, et al. Transition of adolescents with inflammatory bowel disease from pediatric to adult care: a survey of adult gastroenterologists. J Pediatr Gastroenterol Nutr. 2009;48(1): 61-65.

137. Royal College of Physicians of Edinburgh. Think Transition: Developing the Essential Link Between Paediatric and Adult Care. Dalkeith, UK: ARC Scotland; 2008. 
138. Haaland D, Day AS, Otley A. Development and validation of a pediatric IBD knowledge inventory device - the IBD-KID. J Pediatr Gastronterol Nutr. October 16, 2013. [Epub ahead of print.]

139. Zijlstra M, De Bie C, Breij L, et al. Self-efficacy in adolescents with inflammatory bowel disease: A pilot study of the "IBD-yourself", a disease-specific questionnaire. J Crohns Colitis. 2013;7(9): e375-e385.
140. Benchimol EI, Walters TD, Kaufman M, et al. Assessment of knowledge in adolescents with inflammatory bowel disease using a novel transition tool. Inflamm Bowel Dis. 2011;17(5):1131-1137.

141. Crowley R, Wolfe I, Lock K, et al. Improving the transition between paediatric and adult healthcare: a systematic review. Arch Dis Child. 2011;96(6):548-553.

\section{Publish your work in this journal}

Adolescent Health, Medicine and Therapeutics is an international, peer-reviewed, open access journal focusing on health, pathology, and treatment issues specific to the adolescent age group. All aspects of health maintenance, preventative measures and disease treatmen interventions are addressed within the journal and practitioners from all disciplines are invited to submit their work as well as healthcare researchers and patient support groups.. The manuscript management system is completely online and includes a very quick and fair peerreview system. Visit http://www.dovepress.com/testimonials.php to read real quotes from published authors.

Submit your manuscript here: http://www.dovepress.com/adolescent-health-medicine-and-therapeutics-journal 